\title{
STORE ATMOSPHERE MEMODERASI PENGARUH KUALITAS MAKANAN DAN KUALITAS LAYANAN TERHADAP KEPUASAN KONSUMEN (Studi pada Konsumen Moonk Cartil \& Cafe Surabaya)
}

\author{
Ni Nyoman Padang Cakra Binaraesa ${ }^{1, *}$, Imam Hidayat ${ }^{2}$, Marsudi Lestariningsih ${ }^{3}$ \\ ${ }^{1,2,3}$ Sekolah Tinggi Ilmu Ekonomi Indonesia (STIESIA) Surabaya \\ * Penulis korespondensi; Email: ninyomanbinar1995@gmail.com
}

\begin{abstract}
Abstrak: Kualitas Makanan, Kualitas Layanan dan Store Atmosphere memiliki kontribusi penting untuk mencapai Kepuasan Konsumen restoran. Tujuan penelitian untuk menguji dan menganalisis pengaruh Kualitas Makanan dan Kualitas Layanan terhadap Kepuasan Konsumen secara langsung maupun dengan Store Atmosphere sebagai variabel moderasi. Populasi yang digunakan adalah konsumen yang mengunjungi Moonk Cartil \& Cafe. Teknik pengambilan sampel menggunakan purposive sampling dengan jumlah sampel 100 responden. Penelitian ini menggunakan teknik analisis data Moderated Regression Analysis (MRA). Hasil penelitian menunjukkan Kualitas Makanan dan Kualitas Layanan berpengaruh positif dan signifikan terhadap Kepuasan Konsumen, Store Atmosphere tidak memoderasi pengaruh Kualitas Makanan dan Kualitas Layanan terhadap Kepuasan Konsumen.
\end{abstract}

Kata kunci: Kualitas Makanan, Kualitas Layanan, Store Atmosphere dan Kepuasan Konsumen.

\begin{abstract}
Food Quality, Service Quality and Store Atmosphere have important contributions to achieve restaurant customer satisfaction. The research objective was to test and analyze the influence of Food Quality and Service Quality on Consumer Satisfaction directly or with Store Atmosphere as a moderating variable. The population used is consumers who visit Moonk Cartil \& Cafe. The sampling technique used purposive sampling with a sample size of 100 respondents. This study uses data analysis techniques Moderated Regression Analysis (MRA). The results showed that food quality and service quality had a positive and significant effect on consumer satisfaction. Store atmosphere did not moderate the influence of food quality and service quality on consumer satisfaction.
\end{abstract}

Keywords: Food Quality, Service Quality, Store Atmosphere and Customer Satisfaction.

\section{PENDAHULUAN}

Bisnis dibidang kuliner merupakan sektor bisnis yang paling mendominasi kinerja dan usaha ekonomi kreatif. Salah satu segmen usaha kuliner yaitu berbentuk kafe. Kafe identik dengan kesan yang mahal, tempat yang bagus, mewah, unik dan untuk kalangan masyarakat yang berpenghasilan tinggi atau masyarakat yang kaya. Saat ini semua kalangan masyarakat dapat mengunjungi kafe dengan harga yang terjangkau, sajian yang beragam dan tempat yang menarik serta cita rasa yang lezat. Banyaknya kafe yang baru dibuka juga sama dengan banyaknya jumlah kafe yang tutup. Banyak bisnis kuliner yang hanya beroperasi kurang dari 6 bulan sudah tutup karena kurang matangnya perencanaan bisnis saat mulai membuka bisnis restoran. Perencanaan yang matang dapat berarti pelaku bisnis kuliner harus merencanakan bisnis untuk mendapatkan keuntungan yang besar serta mengetahui dan menguasai faktor yang mempengaruhi kesuksesan dalam menjalankan bisnis kuliner atau bisnis restoran dapat meraih kepuasan konsumen sehingga bisnis tersebut dapat bertahan dan berkembang serta tidak gulung tikar.
Kepuasan konsumen sangat penting dilakukan dalam upaya mencegah restoran tutup dan mengalami kerugian bahkan gulung tikar. Menurut Kotler dalam Nggaur (2018) bahwa kepuasan merupakan perasaan senang atau kecewa seseorang yang muncul setelah membandingkan kinerja (hasil) produk yang dipikirkan terhadap kinerja (atau hasil) yang diharapkan. Kepuasan konsumen juga dapat diartikan sebagai sikap dan perasaan yang dimiliki konsumen tentang suatu perusahaan menggambarkan kepuasaan dari konsumen (Hill, 2007:37).

Kualitas makanan dapat diartikan sebagai penilaian terhadap suatu makanan yang diterima oleh pelanggan yang membeli makanan tersebut, kualitas makanan berkaitan dengan pengorbanan yang dikeluarkan oleh pelanggan relatif sama terhadap makanan yang akan diterima konsumen tersebut (Basith, 2014). Kualitas makanan dapat dinilai konsumen setelah konsumen membeli dan merasakan makanan yang ada direstoran lalu dibandingkan dengan pengorbanan yang konsumen keluarkan atau dibandingkan dengan makanan restoran serupa yang sebelumnya pernah dirasakan oleh konsumen. Beberapa penelitian seperti penelitan Bujisic (2014) menunjukkan bahwa kualitas 
makanan adalah atribut penting dari pengalaman konsumen restoran untuk mencapai kepuasan konsumen. Namun, Rony (2017) menemukan kualitas makanan tidak berpengaruh signifikan terhadap kepuasan konsumen di restoran.

Lovelock and Waright (2007:96) kualitas layanan adalah evaluasi kognitif jangka panjang pelanggan terhadap penyerahan layanan suatu perusahaan. Kualitas layanan adalah keseluruhan sikap pelanggan terhadap penyerahan layanan, yang terbentuk dari sejumlah pengalaman layanan yang berhasil maupun yang tidak berhasil dirasakan pelanggan. Penelitian Cahyadi (2014) menghasilkan bahwa kualitas layanan tidak berpengaruh secara signifikan terhadap kepuasan konsumen.

Suasana restoran atau dapat disebut dengan store atmosphere merupakan salah satu hal penting dalam restoran untuk menarik lebih banyak pelanggan dan untuk membangun loyalitas pelanggan (Bujisic, 2014). Kim et al. (2013) mengakui bahwa atmosfer, interior desain, pencahayaan, dan tata ruang makan adalah dimensi penting dari suasana restoran yang mepengaruhi persepsi dan perilaku pelanggan sedangkan menurut Hilaliyah (2017) bahwa kualitas suasana tidak memoderasi pengaruh kualitas produk terhadap kepuasan konsumen dan kualitas suasana tidak memoderasi pengaruh kualitas pelayanan terhadap kepuasan konsumen. Makanan, pelayanan, dan suasana adalah tiga atribut yang paling umum untuk menunjukkan kualitas suatu restoran (Nguyen, 2017).

Penelitian ini difokuskan dengan menggunakan Store atmosphere sebagai variabel moderasi dalam pengaruh kualitas makanan dan kualitas layanan terhadap kepuasan konsumen yang masih jarang digunakan dalam beberapa penelitian sebelumnya dan memiliki beberapa hasil penelitian yang berbeda sehingga sangat menarik diteliti. Store atmosphere yang nyaman dapat mempengaruhi presepsi kualitas makanan dan kualitas layanan untuk mencapai kepuasan konsumen.

Berdasarkan latar belakang, maka rumusan masalah dalam penelitian ini adalah: (1) Apakah kualitas makanan berpengaruh terhadap kepuasan konsumen di Moonk Cartil \& Cafe Surabaya?, (2) Apakah kualitas layanan berpengaruh terhadap kepuasan konsumen di Moonk Cartil \& Cafe Surabaya?, (3) Apakah Store Atmosphere memoderasi pengaruh kualitas makanan terhadap kepuasan konsumen di Moonk Cartil \& Cafe Surabaya? dan (4) Apakah Store Atmosphere memoderasi pengaruh kualitas layanan terhadap kepuasan konsumen di Moonk Cartil \& Cafe Surabaya? Berdasarkan rumusan masalah, maka tujuan penelitian ini adalah: (1) Untuk menguji dan menganalisis pengaruh kualitas makanan terhadap kepuasan konsumen di Moonk Cartil \& Cafe Surabaya, (2) Untuk menguji dan menganalisis pengaruh kualitas layanan terhadap kepuasan konsumen di Moonk Cartil \& Cafe Surabaya, (3) Untuk menguji dan menganalisis pengaruh store atmosphere dalam memoderasi hubungan kualitas makanan terhadap kepuasan konsumen di Moonk Cartil \& Cafe Surabaya dan (4) Untuk menguji dan menganalisis pengaruh store atmosphere dalam memoderasi hubungan kualitas layanan terhadap kepuasan konsumen Moonk Cartil \& Cafe Surabaya.

\section{TINJAUAN TEORITIS}

\section{Kepuasan Konsumen}

Hill (2007:37) menyatakan bahwa kepuasan konsumen dapat digambarkan sebagai sikap dan perasaan yang dimiliki pelanggan tentang suatu perusahaan. Variabel kepuasan konsumen dalam penelitian ini menggunakan indikator pengukuran merujuk pada penelitian Salsabilah (2018) yaitu : (a) Konsumen berniat untuk melakukan pembelian ulang, (b) Konsumen merasa puas dengan makanan yang disajikan, (c) Konsumen merasa puas dengan layanan yang diberikan, (d) Konsumen merasa puas dengan suasana yang diciptakan dan (e) Konsumen berniat untuk merekomendasikan.

\section{Kualitas Makanan}

Menurut Ha dan Jang dalam Bae (2018) menyatakan bahwa kualitas makanan dianggap sebagai dimensi yang menunjukkan kualitas sebuah restoran yang sangat penting. Dalam Salsabilah (2018) terdapat beberapa indikator untuk menentukan kualitas makanan, yaitu : (a) Presentasi Makanan, (b) Rasa, (c) Variasi atau Pilihan Produk, (d) Kesehatan, (e) Kesegaran dan (f) Suhu.

\section{Kualitas Layanan}

Menurut Gronroos dalam Sulistyaningrum (2014) pelayanan merupakan aktifitas yang tidak kasat mata sebagai akibat adanya interaksi antara karyawan dengan pelanggan atau dapat juga disebut dengan tindakan yang bertujuan untuk menyelesaikan permasalahan pelanggan. Variabel kualiatas layanan dalam penelitian ini merujuk pada Hilaliyah (2017) yaitu (a) Tangible, (b) Realibility, (c) Responsivness, (d) Assurance dan (e) Empathy.

\section{Store Atmosphere}

Bujisic (2014) suasana kafe (store atmosphere) merupakan salah satu karakteristik fisik untuk membangun kesan dari suatu tempat serta menarik pelanggan. Dalam Salsabilah (2018) dalam mengukur Store Atmosphere menggunakan beberapa indikator sebagai berikut : (a) Suhu ruangan, (b) Sirkulasi udara, (c) Kebisingan, (d) Musik dan (e) Aroma. 


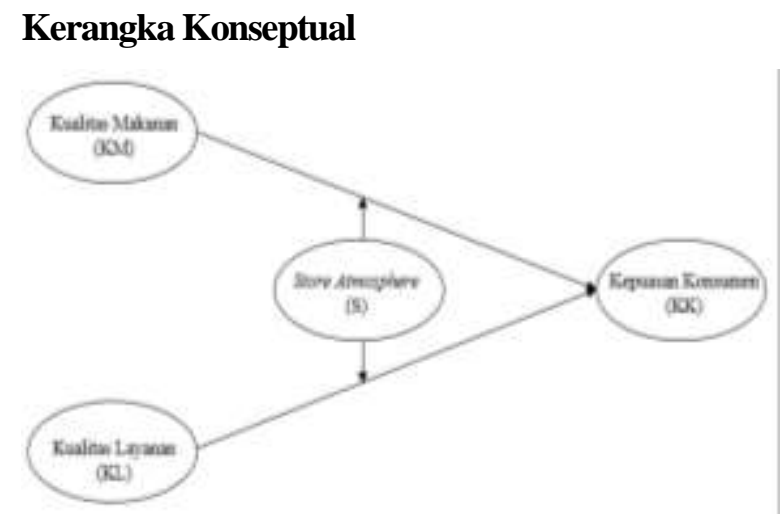

Gambar 1. Kerangka Konseptual

Kerangka konseptual merupakan kesatuan utuh untuk mencari jawaban ilmiah terhadap masalah penelitian yang menjelaskan hubungan antara variabel yang diteliti sehingga berhubungan dengan hasil penelitian sebelumnya sebagai dasar untuk merumuskan hipotesis.

\section{Pengambilan Hipotesis}

\section{Pengaruh Kualitas Makanan terhadap Kepuasan Konsumen}

Ha dan Jang (2010); Ryu dan Han, (2010) menyatakan bahwa kualitas makanan dianggap sebagai dimensi yang menunjukkan kualitas sebuah restoran yang sangat penting. Kotler dan Armstrong (2014:354) "kualitas produk (makanan) merupakan senjata strategis yang potensial untuk mengalahkan pesaing". Jadi, hanya restoran dengan kualitas produk terbaik yang akan tumbuh. Maka dapat dirumuskan hipotesis sebagai berikut:

H1: Kualitas makanan berpengaruh signifikan terhadap kepuasan konsumen

\section{Pengaruh Kualitas Layanan terhadap Kepuasan Konsumen}

Penelitian Liu (2018) menemukan atribut kualitas makanan dan kualitas layanan secara positif dan langsung berhubungan dengan kepuasan pelanggan restoran. Sulistyaningrum (2014) juga menjelaskan bahwa kualitas makanan dan kualitas layanan berpengaruh terhadap kepuasan pelanggan. Dapat dirumuskan hipotesis sebagai berikut:

H2: Kualitas Layanan berpengaruh signifikan terhadap kepuasan konsumen

Pengaruh Kualitas Makanan terhadap Kepuasan Konsumen dengan Store Atmosphere sebagai Variabel Moderating

Lim dalam Sugianto (2013) menyatakan bahwa kepuasan konsumen dipengaruhi oleh suasana restoran yang terdiri dari penataan, dekorasi, musik, kebersihan, dll untuk menciptakan dan membangun citra yang baik dalam pandangan pertama pelanggan dan kesan yang tak terlupakan di benak pelanggan. Dapat dirumuskan hipotesis sebagai berikut:

H3: Store Atmosphere memoderasi pengaruh kualitas makanan terhadap kepuasan konsumen

Pengaruh Kualitas Layanan terhadap Kepuasan Konsumen dengan Store Atmosphere sebagai Variabel Moderating

Kurniawan (2015) menemukan persepsi pelanggan mengenai kualitas layanan berpengaruh positif terhadap kepuasan pelanggan di restoran Korea. Nengsih (2016) menyimpulkan bahwa secara parsial variabel suasana toko berpengaruh signifikan, variabel kualitas pelayanan berpengaruh positif dan signifikan terhadap kepuasan konsumen. Dapat dirumuskan hipotesis sebagai berikut:

H4. Store Atmosphere memoderasi pengaruh kualitas layanan terhadap kepuasan konsumen

\section{METODE PENELITIAN}

Penelitian ini termasuk dalam jenis penelitian kuantitatif, dan jenis penelitiannya adalah kausalitas yang merupakan penelitian untuk menguji hubungan sebab akibat (kausal) antar variabel. Populasi merupakan wilayah generalisasi yang terdiri atas objek atau subjek yang memiliki karakteristik dan kualitas tertentu yang ditetapkan oleh peneliti untuk dipelajari dan kemudian disimpulkan atau ditarik kesimpulan. Sugiyono (2014:16) sampel adalah karakteristik yang dimiliki dan bagian dari jumlah populasi tersebut. Dalam penelitian ini tidak diketahui jumlah populasi secara pasti, maka penelitian ini melakukan pengambilan sampel dengan rumus Unknown Populations. Sugiyono (2013:18), Metode Purposive Sampling digunakan dengan mengambil sampel dengan pertimbangan tertentu dan harus representative atau mewakili populasi yang akan diteliti, pertimbangan yang digunakan yaitu semua konsumen yang berkunjung ke Moonk Cartil and Cafe.

\section{Variabel Penelitian}

Vaiabel yang akan digunakan ke dalam tiga kategori yaitu dua variabel independen, satu variabel moderasi dan satu variabel dependen. Berikut ini adalah hasil pengindentifikasian selengkapnya, yaitu Variabel Independen : Kualitas Makanan (KM) dan Kualitas Layanan (KL), Variabel Moderasi : Store Atmosphere (S) dan Variabel Dependen : Kepuasan Konsumen (KK). 


\section{Teknik Pengumpulan Data}

Analisa statistik deskriptif digunakan dalam penelitian ini untuk memberikan gambaran atau deskripsi mengenai variabel-variabel penelitian yaitu: Kualitas Makanan, Kualitas Layanan, Store Atmosphere dan Kepuasan Konsumen, berdasarkan data dari kuisioner yang terkumpul. Pengukuran variabel dalam metodologi penelitian ini menggunakan skala Likert dimana responden menyatakan tingkat setuju atau tidak setuju mengenai pernyataan dalam kuisioner terdiri dari 5 titik.

\section{Uji Instrumen}

Pengujian validitas bertujuan untuk menguji butir-butir pernyataan yang ada dalam sebuah angket, apakah isi dan butir pernyataan sesuai indikator dari variabel sudah valid atau belum. Pengukuran validitas menggunakan ketentuan jika signifikansi dari $r$ hitung atau $r$ hasil $>r$ tabel maka item variabel adalah valid.

Pengujian realibilitas untuk megetahui jawaban responden terhadap pertanyaan adalah konsisten dari waktu ke waktu. Suatu konstruk atau variabel dapat dikatakan reliabel jika memberikan nilai cronbach alpha $>0,60$.

\section{Teknik Analisis Data}

\section{Analisis Regresi}

Liana (2009) menjelaskan Moderated Regression Analysis (MRA) merupakan pendekatan analitik yang mempertahankan integritas sampel dan memberikan dasar untuk mengontrol pengaruh variabel moderator. Uji ini berarti uji yang dilakukan dengan mengalikan variabel moderasi dengan variabel independen. Analisis regresi variabel moderasi dengan uji interaksi (MRA) dilakukan dengan menggunakan persamaan sebagai berikut :

1. Meregresikan variabel independen (KM dan $\mathrm{KL})$ dan variabel moderasi (S) terhadap variabel dependen (KK) sehingga akan diperoleh persamaan berikut:

$\mathrm{KK}=\alpha+\mathrm{b}_{1} \cdot \mathrm{KM}+\mathrm{b}_{2} \cdot \mathrm{KL}+\mathrm{b}_{3} \cdot \mathrm{S}+\mathrm{e}$

Keterangan:

$\alpha \quad=$ Konstanta

$\mathrm{b}_{1}, \mathrm{~b}_{2}, \mathrm{~b}_{3}=$ Koefisien regresi

e = Error Term, yaitu tingkat kesalahan penduga dalam penelitian.

2. Meregresikan variabel independen (KM dan KL), variabel moderasi (S) dan variabel interaksi (KM, $\mathrm{KL}$ dengan S) terhadap variabel dependen (KK) yaitu:

$$
\begin{aligned}
\mathrm{KK}= & \alpha+\mathrm{b}_{1} \cdot \mathrm{KM}+\mathrm{b}_{2} \cdot \mathrm{KL}+\mathrm{b}_{3} \cdot \mathrm{S}+\mathrm{b}_{4} \cdot(\mathrm{KMxS})+ \\
& \mathrm{b}_{5 .}(\mathrm{KLxS})+\mathrm{e}
\end{aligned}
$$

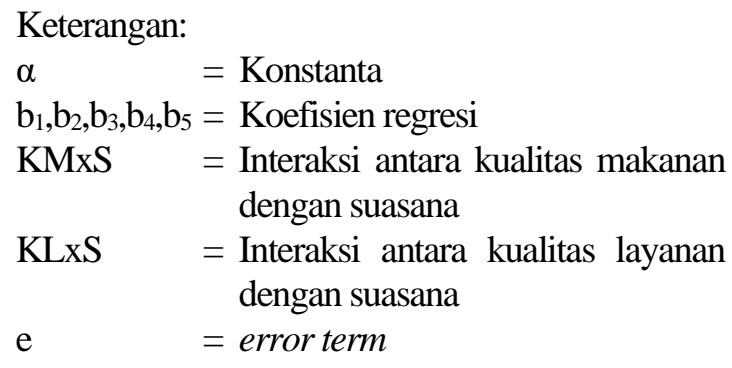

Jika variabel S merupakan variabel moderating, maka koefisien b4 dan b5 harus signifikan pada $\alpha$ (tingkat signifikansi yang ditentukan $<5 \%$ ).

\section{Uji Asumsi Klasik}

\section{Uji Normalitas}

Uji ini menggunakan metode analisis grafik dari normal P-P Plot of Refression Standardizerd Residual, untuk mengetahuinya dapat diasumsikan sebagai berikut: (1) Jika ada titik-titik data menyebar disekitar garis normal dan mengikuti arah diagonal, maka memenuhi asumsi normalitas dan (2) Jika titik-titik data menyebar jauh dari garis diagonal dan atau tidak mengikuti arah garis diagonal, maka model regresi tidak memenuhi asumsi normalitas.

\section{Uji Multikolinearitas}

Ghozali (2012:105) Uji ini menguji model regresi yang ditemukan adanya korelasi antar variabel independen. Pedoman suatu model regresi yang bebas multikoliniearitas adalah Mempunyai nilai VF kurang dari angka 10 atau Mempunyai angka tolerance melebihi 0,01 .

\section{Uji Heterokedastisitas}

Uji ini untuk menguji apakah dalam model regresi tidak terjadi kesamaan variabel dan residual satu pengamatan ke pengamatan lain. Dasar pengambilan keputusan: (1) Jika ada pola, seperti titik yang ada membentuk suatu pola tertentu yang teratur, maka terjadi heterokedastisitas dan (2) Jika tidak ada pola yang jelas serta titik menyebar diatas dan dibawah angka 0 pada sumbu $\mathrm{Y}$, maka tidak terjadi heterokedastisitas.

\section{Uji Kelayakan Model (Goodness of Fit)}

Ghozali (2013:98) Uji kelayakan model yang menunjukkan apakah model regresi fit untuk diolah lebih lanjut. Penerimaan atau penolakan hipotesis menggunakan ketentuan sebagai berikut : (a) Jika nilai signifikansi $\mathrm{F}>0,05$ maka model penelitian dapat dikatakan tidak layak dan (b) Jika nilai signifikansi $\mathrm{F} \leq$ 0,05 maka model penelitian dapat dikatakan layak. 


\section{ANALISIS DAN PEMBAHASAN}

Pengujian validitas dan realibilitas dalam penelitian ini dilakukan dalam pre-sampling menggunakan 30 sampel. Pre-sampling menghasilkan bahwa indikator dalam pertanyaan kuisioner dapat ditetapkan valid karena nilai $r$ tabel sebesar 0,1966 dan semua pertanyaan yang ada dalam kuisioner semua nilai korelasinya lebih besar dari 0,1966. Setiap variabel yang digunakan dalam penelitian juga dapat dikatakan reliable karena nilai Cronbach's Alpha setiap variabel lebih besar dari 0,6 yaitu kualitas makanan sebesar 0,674, kualitas layanan sebesar 0,652, store atmosphere sebesar 0,851 dan kepuasan konsumen sebesar 0,662 .

\section{Analisis Regresi}

Tabel 1. Pengaruh Kualitas Makanan, Kualitas Layanan dan Suasana Terhadap Kepuasan Konsumen

\section{Coefficients $^{a}$}

\begin{tabular}{|c|c|c|c|c|c|c|}
\hline & \multirow{2}{*}{ Model } & \multicolumn{2}{|c|}{$\begin{array}{l}\text { Unstandardized } \\
\text { Coefficients }\end{array}$} & \multirow{2}{*}{$\begin{array}{c}\begin{array}{c}\text { Standardized } \\
\text { Coefficients }\end{array} \\
\text { Beta }\end{array}$} & \multirow[b]{2}{*}{$\mathbf{t}$} & \multirow{2}{*}{ Sig. } \\
\hline & & B & $\begin{array}{l}\text { Std. } \\
\text { Error }\end{array}$ & & & \\
\hline \multirow{4}{*}{1} & (Constant) & 3.463 & 1.880 & & 1.843 & .068 \\
\hline & TOT_KM & .257 & .074 & .321 & 3.497 & .001 \\
\hline & TOT_KL & .141 & .065 & .206 & 2.153 & .034 \\
\hline & TOT_S & .232 & .056 & .343 & 4.173 & .000 \\
\hline
\end{tabular}

a. Dependent Variable: Kepuasan Konsumen

Tabel 1 menghasilkan model persamaan regresi sebagai berikut:

$$
\mathrm{KK}=3,463+0,257 \mathrm{KM}+0,141 \mathrm{KL}+0,232 \mathrm{~S}+\mathrm{e}
$$

Berdasarkan model persamaan regresi yang telah diuraikan dapat dijelaskan bahwa:

1. Nilai konstanta sebesar 3.463 yang artinya adalah nilai kepuasan konsumen akan positif jika variabel kualitas makanan dan kualitas layanan sama dengan nol.

2. Nilai koefisien regresi variabel kualitas makanan (KM) positif sebesar 0,257 . Nilai positif ini memiliki arti hubungan searah, jika KM megalami peningkatan sebesar satu satuan, maka kepuasan konsumen (KK) akan mengalami peningkatan sebesar 0,257 satuan dengan asumsi variabel lain besarnya konstan. Begitu juga sebaliknya.

3. Nilai koefisien regresi variabel kualitas layanan (KL) positif sebesar 0,141. Nilai positif ini memiliki arti hubungan searah, jika KL megalami peningkatan sebesar satu satuan, maka kepuasan konsumen (KK) akan mengalami peningkatan sebesar 0,141 satuan dengan asumsi variabel lain besarnya konstan. Begitu juga sebaliknya

Nilai koefisien regresi variabel store atmosphere (S) positif sebesar 0,232. Nilai positif ini memiliki arti hubungan searah yang menunjukkan bahwa jika $S$ megalami peningkatan sebesar satu satuan, maka KK akan mengalami peningkatan sebesar 0,232 satuan dengan asumsi variabel lain besarnya konstan. Begitu juga sebaliknya.

Tabel 2. Analisis Regre si - Uji MRA Pengaruh Kualitas Makanan dan Kualitas Layanan terhadap Kepuasan Konsumen dengan Suasana sebagai Variabel Moderasi

\begin{tabular}{|c|c|c|c|c|c|c|}
\hline \multicolumn{7}{|c|}{ Coefficients $^{a}$} \\
\hline & \multirow[t]{2}{*}{ Model } & \multicolumn{2}{|c|}{$\begin{array}{l}\text { Unstandardized } \\
\text { Coefficients }\end{array}$} & \multirow{2}{*}{$\begin{array}{c}\begin{array}{c}\text { Standardized } \\
\text { Coefficients }\end{array} \\
\text { Beta }\end{array}$} & \multirow[t]{2}{*}{$\mathbf{t}$} & \multirow[t]{2}{*}{ Sig. } \\
\hline & & B & Std. Error & & & \\
\hline \multirow{6}{*}{1} & (Constant) & -.873 & 10.770 & & -.081 & .936 \\
\hline & TOT_KM & -.335 & .597 & -.418 & -.562 & .576 \\
\hline & TOT_KL & .784 & .529 & 1.144 & 1.480 & .142 \\
\hline & TOT_S & .450 & .520 & .666 & .866 & .389 \\
\hline & TOT_KMxTOT_S & .027 & .028 & 1.433 & .986 & .327 \\
\hline & TOT_KLxTOT_S & -.030 & .025 & -1.939 & -1.223 & .224 \\
\hline
\end{tabular}

Tabel 2 menghasilkan model persamaan regresi sebagai berikut:

$\mathrm{KK}=-0,873-0,335 \mathrm{KM}+0,784 \mathrm{KL}+0,450 \mathrm{~S}+$ $0,027(\mathrm{KMxS})-0,030(\mathrm{KLxS})$

Berdasarkan model persamaan regresi yang telah diuraikan dapat dijelaskan bahwa:

1. Nilai koefisien regresi variabel interaksi (moderasi) antara KM dengan $S$ positif sebesar 0,027 yang artinya adalah KK akan mengalami peningkatan sebesar 0,027 satuan jika variabel interaksi antara $\mathrm{KM}$ dengan $\mathrm{S}$ mengalami peningkatan sebesar satu satuan dengan asumsi variabel lain besarnya konstan dan sebaliknya.

2. Nilai koefisien regresi variabel interaksi (moderasi) antara KL dengan $\mathrm{S}$ negatif sebesar 0,030 yang artinya adalah KK akan mengalami peningkatan sebesar 0,030 satuan jika variabel interaksi antara KL dengan S mengalami penurunan sebesar satu satuan dengan asumsi variabel lain besarnya konstan dan begitu juga sebaliknya.

\section{Uji Asumsi Klasik}

Uji normalitas dilakukan melalui analisis statistik uji Normal P-P Plot of Regression Standardized Residual dan One-Sample Kolmogorov-Smirnov Test.

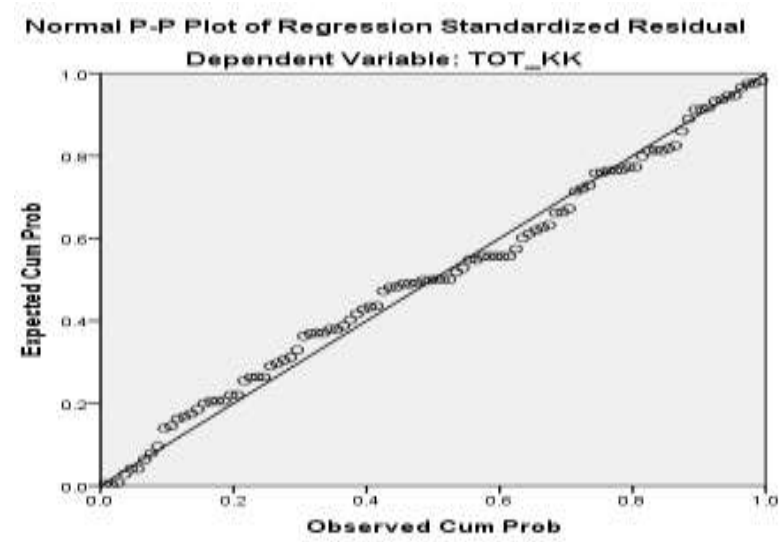

Gambar 2. Uji Normalitas P-Plot 
Tabel 3.Uji Normalitas - One-Sample Kolmogorov-Smirnov Test

\begin{tabular}{llr}
\hline & & $\begin{array}{r}\text { Unstandardized } \\
\text { Residual }\end{array}$ \\
\hline $\mathrm{N}$ & Mean & 100 \\
Normal Parameters ${ }^{a, b}$ & Std. & .0000000 \\
& Deviation & 1.25693156 \\
Most Extreme Differences & Absolute & .062 \\
& Positive & .062 \\
& Negative & -.059 \\
Kolmogorov-Smirnov Z & & .619 \\
Asymp. Sig. (2-tailed) & & .838 \\
\hline a. Test distribution is Normal. & & \\
b. Calculated from data. & &
\end{tabular}

Gambar 2 menunjukkan plot atau titik mengikuti garis dan tidak jauh dari garis diagonal dan nilai kolmogorov-smirnov nya bernilai 0,838 (lebih besar dari 0,05$)$ sehingga data berdistribusi normal.

\section{Uji Multikolinearitas}

Dalam Liana (2009) menyatakan bahwa Regresi dengan Moderated Regression Analysis (MRA) pada umumnya akan terjadi multikolonieritas yang tinggi antara variabel independen, misalkan antara variabel independen dengan variabel moderat. Hal ini disebabkan pada variabel moderat ada unsur variabel independen (KM dan KL). Oleh karena itu, dalam penelitian ini tidak dilakukan uji multikolinearitas.

\section{Uji Heteroskedastisitas}

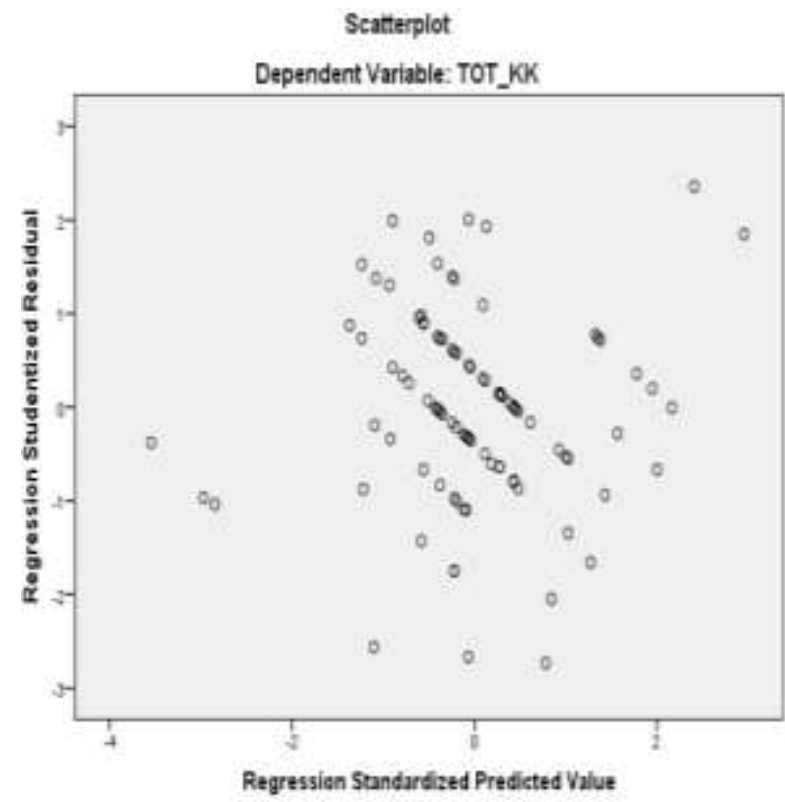

Gambar 3. Uji Heteroskedastisitas

Gambar 3 menunjukkan bahwa dalam penelitian ini tidak terjadi kasus heteroskedastisitas, karena titik atau plot dalam gambar tidak membentuk pola corong atau suatu pola tertentu.

\section{Uji Kelayakan Model}

Tabel 4. Uji Kelayakan Model

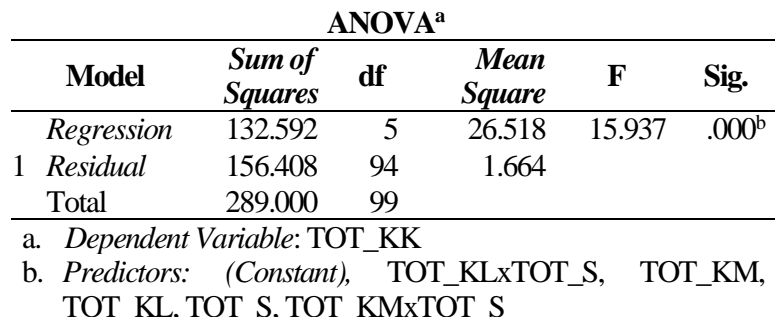

Nilai signifikansi sebesar 0,000 dan memenuhi kriteria kelayakan model harus memiliki nilai siginifikansi $<0,05$. Oleh karena itu, dalam model ini menghasilkan semua variabel independen berpengaruh signifikan secara simultan terhadap variabel dependen kepuasan konsumen sehingga variabel bebas menjelaskan variabel terikat dan model ini layak.

\section{Uji Hipotesis}

\section{Hasil Pengujian hipotesis}

H1: Kualitas makanan berpengaruh terhadap kepuasan konsumen

Berdasarkan Tabel 1 variabel kualitas makanan diperoleh tingkat signifikansi sebesar 0,001 lebih kecil dari $\alpha=0,05$ maka H1 diterima. Oleh sebab itu, hal ini mengartikan bahwa variabel kualitas makanan berpengaruh positif dan signifikan terhadap kepuasan konsumen.

H2: Kualitas layanan berpengaruh terhadap kepuasan konsumen

Berdasarkan Tabel 1 variabel kualitas layanan diperoleh tingkat signifikansi sebesar 0,034 lebih kecil dari $\alpha=0,05$ maka H2 diterima. Oleh sebab itu, hal ini beararti bahwa variabel kualitas layanan berpengaruh positif dan signifikan terhadap kepuasan konsumen.

H3: Store Atmosphere memoderasi pengaruh kualitas makanan terhadap kepuasan konsumen

Berdasarkan Tabel 2 variabel interaksi antara kualitas makanan dengan suasana, diperoleh tingkat signifikansi sebesar 0,327 (lebih besar dari 0,05) sehingga H3 ditolak. Oleh karena itu, menghasilkan bahwa store atmosphere tidak memoderasi pengaruh kualitas makanan terhadap kepuasan konsumen.

H4: Store Atmosphere memoderasi pengaruh kualitas layanan terhadap kepuasan konsumen

Berdasarkan Tabel 2 variabel interaksi antara kualitas layanan dengan suasana, diperoleh tingkat signifikansi sebesar 0,224 (lebih besar dari 0,05) sehingga H4 ditolak. Hal ini menghasilkan bahwa Store Atmosphere tidak memoderasi pengaruh kualitas layanan terhadap kepuasan konsumen. 


\section{Pengaruh Kualitas Makanan terhadap Kepuasan Konsumen}

Penelitian ini menerima $\mathrm{H} 1$ yang menyatakan kualitas makanan berpengaruh positif dan signifikan terhadap kepuasan konsumen. Hal ini ditunjukkan pada Tabel 1 dengan hasil nilai koefisien regresi positif sebesar 0,257 dan nilai signifikansi kualitas makanan sebesar 0,001. Penelitian ini membuktikan bahwa tampilan makanan saat disajikan sangat baik dan sesuai dengan foto di buku menu atau media sosial, rasa makanan di Moonk Cartil \& Cafe juga enak dan cocok dengan kebanyakan responden, variasi menu juga beragam, selain itu, Moonk Cartil \& Cafe menggunakan bahan baku yang segar dan bernutrisi serta memiliki tingkat suhu yang sesuai dengan jenis makanan masing-masing.

\section{Pengaruh Kualitas Layanan terhadap Kepuasan Konsumen}

Penelitian ini menerima $\mathrm{H} 2$ yang menyatakan kualitas layanan berpengaruh positif dan signifikan terhadap kepuasan konsumen. Hal ini ditunjukkan pada Tabel 1 dengan hasil nilai koefisien regresi positif sebesar 0,141 dan tingkat signifikansi kualitas layanan sebesar 0,034. Hal ini menunjukkan bahwa Kualitas layanan yang diberikan kafe kepada konsumen dengan tetap menjaga kebersihan kafe, membentuk karakter karyawan agar konsumen selalu merasa aman dan nyaman, dan juga ruangan kafe yang luas mencapai kapasitas 100 orang tetapi pihak manajemen kafe mengatur tata letak meja konsumen agar tetap merasa nyaman dan melayani konsumen dengan tanggap dan andal sehingga konsumen merasa aman dan nyaman.

\section{Store Atmosphere memoderasi Pengaruh Kualitas Makanan terhadap Kepuasan Konsumen}

Penelitian ini menghasilkan Store Atmosphere tidak memoderasi pengaruh kualitas makanan terhadap kepuasan konsumen dan Store Atmosphere bukan merupakan variabel moderasi antara pengaruh kualitas makanan dengan kepuasan konsumen. Hasil nilai koefisien regresi variabel interaksi antara kualitas makanan dengan store atmosphere positif sebesar 0,027 dan tingkat signifikansi variabel interaksi antara kualitas makanan dengan store atmosphere sebesar 0,327 , nilai signifikansi menunjukkan berpengaruh tidak signifikan dengan tingkat signifikansi variabel interaksi antara kualitas makanan dengan Store Atmosphere lebih besar dari 0,05. Store Atmosphere merupakan variabel yang berpengaruh positif dan signifikan terhadap kepuasan konsumen sebagai variabel independen dapat ditunjukkan dalam Tabel 1 tingkat signifikansinya $<0,05$. Oleh karena itu, H3 ditolak.

\section{Store Atmosphere memoderasi Pengaruh Kualitas Layanan terhadap Kepuasan Konsumen}

Penelitian ini menunjukkan bahwa Store Atmosphere tidak memoderasi pengaruh kualitas layanan terhadap kepuasan konsumen dan Store Atmosphere bukan merupakan variabel moderasi antara pengaruh kualitas layanan dengan kepuasan konsumen. Nilai koefisien regresi variabel interaksi antara kualitas layanan dengan Store Atmosphere negatif sebesar 0,030 dan tingkat signifikansi variabel interaksi antara kualitas layanan dengan Store Atmosphere sebesar 0,224 yang berarti tingkat signifikansi menunjukkan berpengaruh tidak signifikan. Hal ini dapat dikarenakan kualitas layanan Moonk Cartil \& Cafe memiliki kualitas yang baik dan memberikan kenyamanan kepada konsumen sehingga tidak dipengaruhi oleh Store Atmosphere. Store Atmosphere yang diciptakan kafe seperti kebisingan, aroma makanan yang tersebar diruangan kafe, musik yang dimainkan dan sirkulasi udara ruangan yang diciptakan kafe adalah baik sehingga Store Atmosphere merupakan variabel independen yang berpengaruh positif dan signifikan terhadap kepuasan konsumen sebagai variabel independen dapat ditunjukkan dalam Tabel 1 tingkat signifikansinya $<0,05$. Oleh karena itu, H4 ditolak.

\section{KESIMPULAN DAN SARAN}

Kualitas makanan dan kulaitas layanan berpengaruh positif dan signifikan terhadap kepuasan konsumen. Sedangkan Store Atmosphere tidak memoderasi pengaruh kualitas makanan maupun kualitas makanan terhadap kepuasan konsumen. Store Atmosphere juga merupakan variabel yang mempengaruhi langsung variabel kepuasan konsumen.

Moonk Cartil \& Cafe tetap mempertahankan kualitas makanan dan kualitas layanan serta menciptakan suasana yang mendukung terciptanya kepuasan konsumen serta melakukan evaluasi dan inovasi secara berkala bukan hanya pada kualitas makanan saja, tetapi juga dilakukan untuk kualitas layanan yang dan Store Atmosphere agar semua unsur dalam restoran dapat saling menguatkan untuk mencapai kepuasan konsumen.

Store Atmosphere yang diciptakan Moonk Cartil \& Cafe seharusnya lebih efektif agar Store Atmosphere dapat memoderasi pengaruh kualitas makanan dan kualitas layanan kafe yang sudah baik sehingga lebih mudah mencapai kepuasan konsumen.

Bagi peneliti selanjutnya dapat mengembangkan variabel lain seperti variabel harga dan variabel word of mouth sebagai salah satu faktor yang mempengaruhi kepuasan konsumen atau menambah variabel loyalitas pelanggan lanjutan dari kepuasan konsumen. Hal ini bertujuan untuk memperkaya konsep penelitian. 


\section{DAFTAR PUSTAKA}

Bae, S., L. Slevitch dan S. Tomas. 2018. The Effects Of Restaurant Attributes On Satisfaction And Return Patronage Intentions: Evidence From Solo Diners' Experiences In The United States. Cogent Business Management 5: 1-16.

Basith, A., S. Kumadji dan K. Hidayat. 2014. Pengaruh Kualitas Produk Dan Kualitas Pelayanan Terhadap Kepuasan Pelanggan Dan Loyalitas Pelanggan (Survei Pada Pelanggan De'pans Pancake And Waffle Di Kota Malang). Jurnal Administrasi Bisnis (JAB) 11(1): 1-8.

Bujisic, M dan J. Hutchinson. 2014. The Effects of Restaurant Quality Attributes on customer behavioral intentions. International Journal of Contemporary Hospitality Management. 26(8): 1270-1291.

Cahyadi, C. 2014. Pengaruh Kualitas Layanan Dan Kualitas Makanan dengan Peran Moderasi Atmosphere Pada Restoran Sushi Tei Galaxy Mall di Surabaya. Jurnal Ilmiah Mahasiswa Universitas Surabaya 3(1).

Ghozali, I. 2011. Aplikasi Analisis Multivariate dengan Program IBM SPSS 19. Badan Penerbit Universitas Diponegoro. Semarang

Ha, J dan S. S Jang. (2012). The Effects Of Dining Atmospherics On Behavioral Intentions Through Quality Perception. Journal of Services Marketing 26(3) : 204-215.

Hilaliyah, S. 2017. Pengaruh Kualitas Layanan dan Kualitas Produk yang Di Moderasi ole Suasana terhadap kepuasan pelanggan (Studi Pada Mahasiswa Pelanggan Kafe Ria Djenaka Malang). Jurnal Bisnis dan Manajemen. 4(2):172-187.

Hill, N. 2007. Customer Satisfaction: The Customer Experience Through the Customer's Eyes. Book Review. London: The Leadership Factor.

Kim, H.J., J. Park, M. J Kim, dan K. Ryu. 2013. Does Perceived Restaurant Food Healthiness Matter? Its Influence On Value, Satisfaction And Revisit Intentions In Restaurant Operations In South Korea. International Journal of Hospitality Management. $33: 397-405$.

Kotler, P dan G. Armstrong. 2014. Prinsip-Prinsip Manajemen. Edisi Empat Belas Jilid 1. Erlangga. Jakarta.

Kurniawan, E. 2015. Pengaruh Kualitas Layanan Dan Kualitas Makanan Pada Kepuasan Dan Loyalitas Konsumen Restoran Korea 'Myoung Ga' Di Surabaya Dengan Peran Moderasi Atmosfer. Jurnal Ilmiah Mahasiswa Universitas Surabaya. $4(2)$.
Liana, L. 2009. Penggunaan MRA dengan SPSS untuk Menguji Pengaruh Variabel Moderating terhadap Hubungan antara Variabel Independen dan Variabel H7 Dependen. Jurnal Teknologi Informasi DINAMIK. 14(2) :90-97.

Liu, P dan Y. Ching. 2018. Exploring Factors On Customers' Restaurant Choice: An Analysis Of Restaurant Attributes. British Food Journal.

Lovelock, C. H dan L. K. Waright. 2007. Manajemen Pemasaran Jasa. Cetakan II. Jakarta. PT Indeks.

Nengsih, D. R. 2016. Pengaruh Suasana Toko, Kualitas Pelayanan Dan Diversifikasi Produk Terhadap Kepuasan Konsumen (Studi Pada Granny's Nest Cafe And Resto Di Bandar Lampung). Skripsi. Universitas Lampung. Lampung.

Nggaur, D. A. 2018. Pengaruh Harga, Kualitas Pelayanan, Dan Lingkungan Fisik Terhadap Kepuasan Pelanggan. Studi Kasus Kafe Markobar Manado. Skripsi. Universitas Sanata Dharma. Yogyakarta.

Nguyen, Q., T. M. Nisar, D. Knox dan G. P. Prabhakar. 2017. Understanding customer satisfaction in the UK Quick Service Resaurant industry. British Food Journal.

Rony. 2017. Pengaruh Kualitas produk dan Suasana Cafe (Store Atmhosphere Terhadap Keputusan Pembelian Konsumen dan Dampaknya Terhadap Kepuasan Konsumen (Studi Kasus Pada Alila Cafe Pontianak). Pontianak. Universitas Tanjungpura.

Ryu, K dan H. Han. 2010. Influence Of The Quality Of Food, Service, And Physical Environment On Customer Satisfaction And Behavioral Intention In Quick-Casual Restaurants: Moderating Role Of Perceived Price. Journal of Hospitality \& Tourism Research 34(3):310-329.

Salsabilah, T dan Sunarti. 2018. Pengaruh Food Quality, Dining Atmosphere dan Kesesuaian Harga Terhadap Kepuasan Pelanggan Cafe Ria Djenaka Shining Batu. Jurnal Administrasi Bisnis (JAB) 54 (1)

Sugianto, J dan S. Sugiharto. 2013. Analisa Pengaruh Service Quality, Food Quality, Dan Price Terhadap Kepuasan Pelanggan Restoran Yung Ho Surabaya. Jurnal Manajemen Pemasaran Petra 1(2): 1-10.

Sugiyono. 2014. Statistik untuk Penelitian. Alfabeta. Bandung.

Sulistyaningrum, U. 2014. Pengaruh Kualitas Produk dan Layanan Terhadap Kepuasan Konsumen Di Restoran Koki Tappanyaki Express. Skripsi. Universitas Negeri Yogyakarta. Yogyakarta. 